\title{
ANTÍGONA Y PRÍAMO: DOS PERSONAJES ACTUALES
}

\section{MIGUEL CASTILLO DIDIER UNIVERSIDAD DE CHILE, CHILE}

Resumen: En la vastedad del legado clásico, se distinguen figuras arquetípicas, sobre las que el hombre ha reflexionado y seguirá reflexionando. Prometeo, Orfeo, Edipo, Antígona, Odiseo, Aquiles, Príamo, Penélope, Alceste, el perro Argos... Algunos de ellos adquieren especial presencia en nuestro tiempo, tiempo en que la desaparición forzada de personas, que tiene una larga y terrible parte en la historia humana, ha reaparecido en el siglo pasado y en el presente en no pocas latitudes. Ante la terrible realidad que ha afectado a nuestro país bajo la dictadura cívico-militar de 1973-1989, las figuras de Antígona y de Príamo adquieren una desgarradora actualidad

Palabras clave: Desaparición forzada de personas, Antígona, Príamo

\section{ANTIGONE AND PRIAM: TWO PRESENT FIGURES}

Abstract: In the vastness of the classical legacy, archetypal figures are distinguished, on which man has reflected and will continue to reflect. Prometheus, Orpheus, Oedipus, Antigone, Odysseus, Achilles, Priam, Penelope, Alcestes, the dog Argos ... Some of them acquire special presence in our time, time in which the forced disappearance of people, which has a long and terrible part in the human history ,has reappeared in the last century and in the present in many latitudes. Given the terrible reality that has affected our country under the civil-military dictatorship of 1973-1989, the figures of Antigone and Príamo acquire a heartbreaking current

Keywords: Forced disappearance of people, Antigone, Priam

Recibido: 25.01.2017 - Aceptado:21.04.2017

Correspondencia: Miguel Castillo Didier, Email: micastilgriego@gmail.com

Director del Centro de Estudios Griegos, Bizantinos y Neohelénicos Profesor Titular Universidad de Chile. Casilla 435.3 Santiago Chile. 


\section{ANTÍGONA Y PRÍAMO: DOS PERSONAJES ACTUALES}

$\mathrm{L}$ a desaparición forzada de personas tiene una larga y terrible presencia en la historia. Para recordar uno de los ejemplos más estremecedores, mencionemos el genocidio de hebreos, gitanos, homosexuales y comunistas llevado a cabo por el nacismo, en el siglo pasado. Los millones de personas que fueron muertas en los diversos campos habilitados para el exterminio, desaparecieron. Desaparecieron para sus parientes, para sus amigos, para sus conciudadanos. Desaparecieron en el mundo. Se sabe cómo murieron y más o menos en qué época, dentro del tiempo en que funcionó la máquina de exterminio. Pero desaparecieron: un día fueron apresados por los soldados nacis y ni siquiera sus cenizas aparecieron.

En América Latina, a menor escala que en la Alemania naci, ha habido máquinas de exterminio. La dictadura instaló una en Chile para exterminar opositores, haciéndolos desaparecer. El asesinato de una persona por esa maquinaria siniestra trae para su entorno consecuencias que se prolongan indefinidamente. Desde la angustiosa búsqueda por los parientes en los primeros días y hasta meses, hasta el convencimiento de que ha desaparecido, hasta el dolor de asumir que no lo verán más y de que no podrán siquiera tener sus restos para sepultarla. Son diversos los derechos humanos fundamentales violados, hasta aquel que ha sido considerado sagrado en todas las culturas: enterrar a los muertos y tener un lugar donde recordarlos, rezar si se es creyente, colocar una flor, encender una vela.

En relación con esta terrible realidad que se vivió y que aún se vive por no pocas familias en nuestro país, es imposible no recordar dos personajes de la cultura griega.

En el legado griego, de cuya vastedad y complejidad, se pueden distinguir figuras arquetípicas a las que el hombre ha vuelto a través de los siglos y sobre las que ha reflexionado y seguramente seguirá reflexionando. Prometeo, Orfeo, Edipo, Antígona, Odiseo, Aquiles, Príamo, Penélope, Helena, Alcestes, el perro Argos. Cuántos personajes, nimbados por la luz de la sabiduría, de la virtud, del heroísmo, del amor, de la tragedia, de la fatalidad.

Del dramaturgo recordaremos la tragedia Antígona. Lo que la orden de un gobernante absoluto niega en esa obra es el último derecho negado a los parientes de un desaparecido: el derecho a enterrar al ser 
querido.

Antígona fue representada el año 442 según el criterio generalizado entre los especialistas. Desde entonces, la obra nunca ha sido olvidada. Como escribió Jaeger: "El efecto inextinguible de Sófocles sobre el hombre actual, a base de su posición imperecedera en la literatura universal, son sus caracteres. Si nos preguntamos cuáles son las creaciones de los trágicos griegos que viven en la fantasía de los hombres, con independencia de la escena y de su conexión con el drama, veremos que las de Sófocles ocupan el primer lugar"'. Uno de esos personajes es Antígona.

George Steiner, por su parte, se refiere a la tragedia en estos términos: "En la constelación de las siete tragedias conservadas de Sófocles, Antígona es la estrella más hermosa [...]. No es sólo la más hermosa de las tragedias griegas, sino, además, de todas las obras que ha creado el espíritu humano, es la que toca más la perfección"2.

Lasso de la Vega destaca el porqué de la permanencia de ese personaje: "En nombre de aquellas leyes que no son de hoy ni de ayer, sino de siempre, Antígona, en pugna con la ley humana [...], le lleva la contra al tirano, entierra simbólicamente su su hermano y salva aquel deber intocable, a costa de su propia vida"3. Agustín Blánquez utiliza expresiones semejantes para caracterizar la acción de Antígona en la obra: "En cumplimiento de la ley moral, de esas leyes no escritas que afirman los derechos de la conciencia humana, desafía a la muerte y la afronta voluntariamente para cumplir la ley piadosa de dar sepultura a Polínice [...] su hermano, contraviniendo la prohibición decretada `por el rey de la ciudad, Creonte"'4.

1 W. Jaeger: Paideia: los ideales de la cultura griega, F. C. E., Buenos Aires 1993, p. 250.

2 G. Steiner: Las Antígonas El mito de Antígona en la literatura, las artes y el pensamiento de la Antigua Grecia. Cit. por M. Lamberidu Pothia En Revista Thémata Logotejnías 18-21, 2001-2002 (Atenas), p. 407.

3 J. Lasso de la Vega "Introducción" a Sófocles: Tragedias, traducción y notas Assela Alamilo. Editorial Gredos, Madrid 2002, p.80.

4 A. Blánquez: “La vida y el teatro de Sófocles”. En Sófocles: Dramas y tragedias. Traducción, prólogo y notas Agustín Blánquez, Editorial Iberia, Barcelona 1967, p. XII. 
Con razón, Joel Sáez anota que también "Antígona [...] ha sido probablemente uno de los personajes trágicos más frecuentados en la dramaturgia posterior y ha merecido libros en que tal trayectoria y sus distintas interpretaciones ha sido objeto de análisis, como el ya imprescindible de George Steiner".

J. Sáez y R. Pineda ven una voluntad muy amplia en la actitud de Antígona ante la orden que le prohibía sepultar a su hermano. Para ellos, "Antígona intentaba transformar las relaciones de violencia imperantes en relaciones de concordia y amor, y al no ser comprendida es condenada a muerte sin que alcance los anhelos a los que se consagra. Antígona quisiera hallar un sitio tranquilo para el padre impositivo, detener la guerra fratricida entre los hermanos $y$, hacer entender al estado el valor interno de la muerte de Polinices al que ella no puede ver como un traidor. Ella no ve sus sueños realizados; ni los personales ni los sociales, y se extingue como la llama de la vela que sofoca la copa en la imagen final de espectáculo"s.

Ahora bien, Antígona pierde la vida por reivindicar el derecho a sepultar a su hermano Polínice. Desafía la orden de la tiranía. Pero los deudos de los detenidos desaparecidos ni siquiera podrían sacrificar sus vidas por ejercer el derecho a enterrar a sus seres queridos. La dictadura los puso en la imposibilidad de hacerlo, haciendo desaparecer todo vestigio de muchas de sus víctimas. Sólo algunas personas han logrado después de muchos años, hasta más de cuarenta años, encontrar algunos escasos y mínimos trozos de huesos de aquellos asesinados.

La orden del tirano prohíbe "darle sepultura y que se le llore; hay que dejarlo sin lágrimas e insepulto hasta que sea fácil presa de las aves". La prohibición se extiende pues también al llorar y al lamentarse por la muerte de Polínice. Se dirá que es imposible prohibir esas manifestaciones humanas. Sin embargo, en cierto modo hasta eso prohibió la dictadura chilena. ¿Por qué lo decimos? Porque en vez del llanto o lamento que naturalmente sigue a la muerte de un ser querido, en el caso de los desaparecidos aquél ha quedado reemplazado por la angustia que durante un tiempo, que se hace eterno, domina a aquellos que saben que su familiar ha sido detenido. La esperanza de encontrarlo con vida los moviliza en la búsqueda. La esperanza se va perdiendo poco a poco y va siendo reemplazada por la idea de que tiene que estar muerto. Pero ¿cuándo y

5 Sáez, J. y Pineda, R.: Palabras desde el silencio. Ediciones Sed de Belleza, Santa Clara (Cuba) 2002, p. 82-83. 
cómo terminó su vida? Ya no hay lágrimas para ese dolor mezclado con punzante incertidumbre. Así pues, el terrible sistema de aniquilar personas se convirtió en una especie de prohibición de las lágrimas.

El drama de los desaparecidos trae a la mente otro personaje de la poesía griega: Príamo. El anciano rey de Troya es acaso el personaje más trágico de la Ilíada. Al frente de una ciudad víctima de una guerra absurda e injusta, pierde uno a uno a todos sus hijos. Y presencia la muerte del más querido de ellos, el de alma más noble: Héctor.

Como sabemos, la rapsodia XXIV del poema, casi entera, está dedicada al rescate del cadáver de Héctor Príamo. La idea de que el padre vaya a pedir a Aquiles que le entregue el cuerpo de su hijo, parte en esta rapsodia de Zeus. Se ha dicho que la conmovedora escena de encuentro de Aquiles y el rey troyano está decidida e implementada por iniciativa divina. Pero en realidad, un pasaje de la rapsodia XXII muestra que ello no es así. Allí, en los versos 416 y siguientes, el atribulado padre trata de desprenderse de los brazos que lo retienen para correr donde Aquiles y clamar por su cadáver. Haciendo esfuerzos por zafarse de quienes lo han detenido, exclama desesperado: "Dejadme, amigos, por más intranquilos que estéis; permitidme que, saliendo solo de la ciudad, vaya a las naves aqueas y ruegue a ese hombre pernicioso y violento: acaso respete mi edad

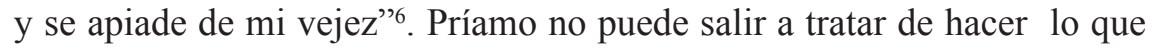
intenta, pues se lo impiden físicamente los familiares.

Pero en la última rapsodia, todo se ve dispuesto por la voluntad de Zeus. A pesar de ello, la escena del encuentro del padre, que lleva el terrible dolor de la muerte de su hijo, con el matador de éste, que por su parte aloja en su alma el gran dolor por la muerte de su amigo Patroclo a manos de Héctor, es hondamente conmovedora. Oddone Longo se refiere con alguna extensión a su significado. Dice así:

"La Ilíada es un poema cruel, por momentos inhumano en los comportamientos tanto de los dioses como de los hombres que, presentes a menudo en primera persona en el campo de batalla, dirigen las vicisitudes de aquellos. En el poema, la sangre impregna el polvo de la llanura y enturbia el agua de los ríos, en una masacre sin piedad, sólo en parte ennoblecida por la observancia de las reglas de la guerra épica, por la prestancia y

6 Homero (1954) Ilíada XX, 416 y s. En Homero Obras Completas, Traducción Luis Segalá Estalella, Prólogo Arturo Marasso. Buenos Aires: Editorial El Ateneo. 
valentía de los aristocráticos combatientes. Fútiles en sustancia, cuestiones de principio más que otra cosa, son los motivos tanto de la guerra como de la ira de Aquiles: no se trata de nada más importante que raptos de mujeres y substracciones de botín, que, sin embargo, son acontecimientos capaces de desencadenar las cóleras y luchas y masacres que caracterizan este trágico íncipit de la literatura universal. Y sin embargo, más allá de tanta sangre derramada, de tantas crueldades cometidas, más allá de la propia conducta caprichosa y despiadada de los dioses, más allá de todo esto, los dos últimos cantos, el último en particular, abren en ese cielo tenebroso y ensangrentado un rayo de esperanza, porque al final lo que prevalece es la piedad por el vencido, el respeto por el dolor que empareja a todos los seres humanos. Sin hacer retórica, nos parece posible afirmar que el último canto de la Ilíada es lo que marca el nacimiento del humanismo griego"7.

Y Lesky caracteriza de modo semejante el final del poema: "En aquella escena en la que Aquiles y Príamo, después de todo el rigor de la lucha, de todo el sufrimiento, de toda la crueldad de una venganza carente de sentido, encuentra la Ilíada su culminación y se marca el comienzo de la trayectoria del humanismo occidental"s.

La búsqueda de los restos del hijo muerto para darle sepultura nos trae sin duda a la mente la búsqueda de los cuerpos de aquellos a quienes la dictadura hizo desaparecer. Pero Príamo tenía al menos la certidumbre de la muerte de su hijo, pues la había presenciado desde lo alto de las murallas de Troya. No había tenido el largo período de esperanza, angustia e incertidumbre sobre la vida del ser querido apresado por los esbirros de la DINA, que han sufrido todos los parientes, amigos y cercanos de los detenidos desaparecidos, antes que a llegar a convencerse que estaban muertos.

La cercanía del personaje homérico a las situaciones vividas en Chile, Argentina, Uruguay y otros países, se acentúa al ser tratado por otro poeta griego: Constantino Kavafis. Casi tres mil años después de Homero, Kavafis retoma al personaje. Lo retoma desde la figura de la rapsodia XXII, la figura del padre que quiere ir solo a pedir el cadáver de Héctor. Y así borra a todos aquellos, a los dioses y los hombres, que se mueven en la

7 O. Longo (2009) El universo de los griegos Actualidad y distancias. Traducción St. Mastrangelo. Barcelona: Editorial Acantilado.

8 A Lesky (1968) Historia de la literatura griega, traducción J. M. Díaz y B. Romero. Madrid: Editorial Gredos. 
rapsodia XXIV y a los que acompañan a Príamo. En el poema de Kavafis, Príamo, como en la rapsodia XXII de la Ilíada, decide ir solo, reúne solo los objetos para el rescate, sale solo y conduce solo su carruaje. Nosotros desde la lectura acompañamos a ese padre, agobiado de dolor, que va en busca de los restos de su hijo. Y en la realidad del poema no sabemos cómo terminará su intento, si podrá recuperar el cuerpo de Héctor.

\section{Viaje nocturno de Príamo (1893)}

Dolor y lamento en Ilión. / La tierra de Troya en desesperanza amarga y en temor al gran Héctor Priámida llora.

El treno estridente grave resuena. / Ni un alma queda en Troya no doliente, que el recuerdo de Héctor olvide.

Mas es vano, inútil / el mucho lamento en una ciudad atormentada: sordo es el adverso destino.

Detestando Príamo lo inútil, / oro saca del tesoro; agrega marmitas, tapices, y manto; y también

túnicas, trípodes, una cantidad espléndida /de peplos, y todo lo que apropiado juzga, y sobre su caro lo carga.

Quiere con rescate del terrible / enemigo recuperar el cuerpo de su hijo, y con augustas exequias honrarlo.

Sale en la noche silenciosa. / Habla poco. Por único pensamiento ahora tiene veloz, veloz que corra su carruaje. 
Tenebroso extiéndese el camino. / Lúgubre gime el viento y se lamenta.

Grazna a lo lejos un ominoso cuervo.

Aquí el aullido de un perro se escucha; / allí, cual susurro una liebre de rápidos pies cruza.

E1 rey azota, azota los caballos.

Sombras de la llanura despiértanse / siniestras, y se preguntan por qué con tanta prisa

vuela el Dardánida hacia los navíos de argivos asesinos y de aqueos / funestos.

Pero el rey a esas cosas no atiende; basta que su carro veloz, veloz corra .

Es éste entonces un poema de la soledad. Y en el dolor y los esfuerzos del anciano rey podemos ver reflejados el dolor y la lucha de cuántos seres humanos que han buscado los restos de sus hijos, esposos, padres, hermanos, desaparecidos en Chile y en nuestra América.

\section{REFERENCIAS BIBLIOGRÁFICAS}

BLÁNQUEZ, A. (1967) "La vida y el teatro de Sófocles". En Sófocles: Dramas y tragedias. Traducción, prólogo y notas Agustín Blánquez. Barcelona: Editorial Iberia.

CASTILLO DIDIER, M. (2008) Kavafis íntegro. $3^{\text {a }}$ edición, Santiago: Coedición Centro de Estudios Griegos Tajamar Ediciones.

HOMERO (1954) Ilíada XX, 416 y s. En Homero Obras Completas. Traducción Luis Segalá Estalella, Prólogo Arturo Marasso. Buenos Aires: Editorial El Ateneo.

JAEGER, W. (1993) Paideia: los ideales de la cultura griega, F. C. E., Buenos Aires 1993.

9 El texto en M. Castillo Didier: Kavafis íntegro, Coedición Centro de Estudios Griegos y Tajamar Editores, $3^{\text {a }}$ edición, Santiago 2008, pp. 560 - 562. 
LASSO DE LA VEGA, J. (2002) “Introducción” a Sófocles: Tragedias, traducción y notas Assela Alamiro. Madrid: Editorial Gredos.

LESKY, A. (1968) Historia de la literatura griega, traducción J. M. Díaz y B. Romero. Madrid: Editorial Gredos.

LONGO, O. (2009) El universo de los griegos Actualidad y distancias. Traducción St. Mastrangelo. Barcelona Editorial Acantilado..

SÁEZ, J. Y PINEDA, R. (2002) Palabras desde el silencio. Santa Clara: Ediciones Sed de Belleza.

STEINER, G. (2001-2002) Las Antígonas El mito de Antígona en la literatura, las artes y el pensamiento de la Antigua Grecia. Cit. por M. Lamberidu Pothia. En Revista Thémata Logotejnías 18-21 (Atenas). 